\title{
A French approach to cost-effectiveness analysis?
}

\author{
Gérard de Pouvourville
}

Published online: 3 November 2010

(C) Springer-Verlag 2010

France is still considered as a paradigmatic country in terms of its refusal to consider health economic assessments when deciding on access to reimbursement and pricing of drugs and medical devices. In a recent editorial of this journal [1], Claude Le Pen has argued that this may reflect a "continental" view of health economics and in particular a specific philosophical conception of illness, health and medicine, which resists the idea that "health and illness differ only in quantitative states" and thus "cannot be plotted in the same space".

My purpose here is not to challenge this ambitious view, and it is fair to say that Claude Le Pen also mentioned some founding principles of the French Sécurité Sociale implemented in 1945. In particular, as far as new medicines are concerned, the French "Code de la Sécurité Sociale" states that all drugs with a favourable benefit/risk ratio, as assessed by the Transparency Commission, should be accessible to patients through reimbursement, independent of their price. The only mention of economics in the code is in its Article R163- $1^{1}$ that states that medicines should not be reimbursed if they "will potentially induce unjustified expenditures for the Sickness Fund, either because their public health interest is low because their efficacy is not well proven, or because they bring a minor contribution in existing therapeutic strategies, or because of the absence of severity of the diseases they address". ${ }^{2}$

Thus, clinical efficacy is the leading criterion in access to reimbursement, independent of any price consideration. A drug will not be reimbursed if it is not considered as truly effective or if the health problem it addresses is not

G. de Pouvourville ( $\square$ )

ESSEC Business School, 95021 Cergy Pontoise Cedex, France

e-mail: pouvourville@essec.fr "serious" enough that it merits solidarity (the usual example given is drugs to treat erectile dysfunctions).

Besides these founding principles, health economics are also strongly opposed by the community of medical experts who inform reimbursement decisions. To illustrate this opposition, which may be present in other countries, language used by this community is quite explicit: they will use the term "scientific assessment" when referring to the clinical evaluation of new products as opposed to an "economic assessment", which clearly states that the latter is not truly scientific.

In this context, the door is narrow for health economics and cost-effectiveness analysis in the French context. Nevertheless, slow progress has been made in the past 3 years. At the end of 2007, there was a major change in the mandate of the $\mathrm{HAS}^{3}$ the French national HTA agency, which by law has now to document economic efficiency alongside with clinical evidence. The HAS created a new commission, the Commission for Economic and Public Health Evaluation (CEESP). It comprises 26 members, chaired by Professor Lise Rochaix, an eminent health economist; eight members are economists, six are public health specialists or methodologists, four are clinicians, two are representatives of patients' associations. The remainder are a pharmacists trained in health economics, a jurist, a psychiatrist, a high rank civil servant, a sociologist, and a philosopher. Although economists are the most important subgroup, the composition reflects the perspective of the CEESP, which is to perform health technology assessment on all relevant dimensions to inform the decision maker.

\footnotetext{
${ }^{1}$ Code de la Sécurité Sociale. Livre 1, Titre 6, Chapitre 3.

2 Author's translation.

3 Haute Autorité de Santé.
} 
The CEESP covers all health interventions, be they drugs, medical devices, screening programs, diagnostic and therapeutic procedures, etc. In principle, the Commission should give advices at the following levels:

- at the first listing of a medical technology and beyond the assessment of the efficacy/safety ratio and the definition of the target population, document the system impact of the technology and identify additional data required for future reassessment, if required by $H A S$;

- at time of reassessment, provide with cost-effectiveness/cost-benefit analysis;

- permanently provide decision makers with full HTA including all relevant dimensions (economic, ethical, sociological, legal).

A recently published report of the $\mathrm{CEESP}^{4}$ will illustrate how cost-effectiveness may be used in the future in France. As of July 2010, the HAS published the results of a study, the aim of which was to provide the government and the sickness fund with recommendations on the most efficient use of statins. This work was undertaken on the request of the Ministry of Health, but it also was in line with ongoing actions taken by the sickness fund and directed towards physicians aiming at encouraging generic prescriptions. The published report covers the following issues:

- Clinical recommendations on the use of statins in lipidlowering strategies, based on published evidence. Such recommendations were to adjust lipid-lowering treatments to patients profiles, in terms of cardiovascular and metabolic risk factors. One particular issue was that of the relative morbid-mortality outcomes of statins in primary prevention (patients with risk factors but no previous event) and secondary prevention.

- Recommendations based on the comparison of the cost of the use of different statins, since the class covers both generic molecules (simvastatin, fluvastatin and pravastatin) and molecules still under licence protection (atorvastatin and rosuvastatin).

The economic approach to the question was based on the following line of arguments. First, it was acknowledged by authors that lipid-lowering treatments with statins had demonstrated a benefit in reducing mortality. This benefit was considered by authors as a class effect; heterogeneity of populations included in trials was such that it was not possible to individualize differential benefits for each statin. It was nevertheless recognized that statins did have a differential potency in reducing LDL cholesterol, with an

\footnotetext{
4 HAS. Efficacité et efficience des hypolipémaints: une analyse centrée sur les statines, July 22, 2010. http://www.has-sante.fr/portail/ jcms/c_968816/efficacite-et-efficience-des-hypolipemiants-uneanalyse-centree-sur-les-statines.
}

advantage to the more recent statins, which can be prescribed at lower doses. The report used data from the STELLAR [2] clinical trial and the meta-analysis from Law [3] to establish an equivalency matrix in terms of percentage reduction of LDL cholesterol according to different doses of marketed molecules. The review of the literature also led to consider that there were no differences in toxicity, at doses currently prescribed in France. Differential activity of statins on HDL cholesterol was not considered, since the benefits from controlling this parameter were not considered as sufficiently established to justify an indication.

Authors then proceeded to the calculation of the cost of reduction of $1 \mathrm{~g} / \mathrm{L}$ of LDL cholesterol, for each molecule/ dose couple. More accurately, the calculation consisted of the estimation of the annual cost of treatment related to the percentage of reduction of LDL.

The main conclusions of the economic analysis were the following, taking into account actual public prices of each molecule:

- For low to moderate hypercholesterolemia (with a $40 \%$ or less reduction expected of LDL), generic simvastatin was recommended with a dosage adapted to the therapeutic target $(10,20$ or $40 \mathrm{mg})$ as being the most efficient treatment. Notice that if the target is a reduction of $30-40 \%$ of LDL, atorvastatin $10 \mathrm{mg}$ and rosuvastatin $5 \mathrm{mg}$ were considered as equivalent to simvastatin $40 \mathrm{mg}$ in terms of cost-efficacy.

- For moderate to severe hypercholesterolemia ( $\geq 40 \%$ reduction of LDL cholesterol), only rosuvastatin and atorvastatin allow to reach the therapeutic target. If the target reduction is between 40 and $50 \%$, rosuvastatin 10 or $20 \mathrm{mg}$ is more cost-effective than atorvastatin 20 or $40 \mathrm{mg}$, if the target exceeds $50 \%$ then only atorvastatin $80 \mathrm{mg}$ is useful.

- In all cases, for the same expected target, the generic presentation should be preferred.

Finally, based on a review of published cost-effectiveness analyses, authors do not recommend primary prevention for patients with a low cardiovascular risk. This appraisal is not formally based on an explicit cost-perQALY threshold, but on the observation that in this indication, published ICERs are significantly higher than for primary prevention for high risk patients or secondary prevention.

What can be extrapolated from this example for the future of health economics in France? On one hand, it is most plausible that in the near future, economic analysis will be used mainly to assess the relative efficiency of treatments in given therapeutic domains, and not across the board; this is quite similar to IQWIG's approach in Germany. The other similarity with Germany has been the use by authors of the 
report of the plot of existing alternatives and the identification of an efficiency frontier, but based here on a onedimensional measure of efficacy, the percentage reduction of LDL cholesterol. The recommendations clearly leave a large room to clinical recommendations: once the patient's risk has been assessed and his/her need for lipid-lowering treatment, the recommendation bears only on the choice of the molecule based on its cost-efficacy ratio. Overall, the emphasis is more on the efficient use of existing treatments than on the opportunity of admitting a treatment for reimbursement. Could this type of analysis been done earlier in the initial market access process? One has to recall that in France, this would be subsequent to (a) the advice of the Transparency Commission which recommends access to reimbursement and defines the place of a new entity in existing therapeutic strategies, (b) the price setting negotiation with the Pricing Committee. Only under this set of constraints could the CEESP then analyse the relative costeffectiveness of different strategies according to cost of treatments. It is more probable that alongside similar economic assessments as the one reported here, cost- effectiveness analyses will be expected from companies when a drug is reassessed by the Transparency Commission 5 years after its first approval, based on post-launch studies that companies will have to perform. If this is the case, companies must expect to be required to perform large comparative real-world studies. Actually, this is already what is happening to assess the relative effectiveness of new products.

\section{References}

1. Le Pen, C.: Is there a «continental» view of health economics evaluation? Eur. J. Health Econ. 10, 121-123 (2009)

2. Jones, P.H., Davidson, M.H., Stein, E.A., Bays, H.E., McKenney, J.M., Miller, E., et al.: Comparison of the efficacy and safety of rosuvastatin versusatorvastatin, simvastatin, and pravastatin across doses (STELLAR* Trial). Am. J. Cardiol. 92(2), 152-160 (2003)

3. Law, M., Wald, N.J., Rudnicka, A.R.: Quantifying effect of statins on low density lipoprotein cholesterol, ischaemic heart disease and stroke: systematic review and meta-analysis. BMJ 326, 1423 (2003) 